\title{
Monetary union without fiscal coordination may discipline policymakers
}

Citation for published version (APA):

Beetsma, R., \& Bovenberg, A. L. (1995). Monetary union without fiscal coordination may discipline policymakers. METEOR, Maastricht University School of Business and Economics. METEOR Research Memorandum No. 024 https://doi.org/10.26481/umamet.1995024

Document status and date:

Published: 01/01/1995

DOI:

10.26481/umamet.1995024

Document Version:

Publisher's PDF, also known as Version of record

\section{Please check the document version of this publication:}

- A submitted manuscript is the version of the article upon submission and before peer-review. There can be important differences between the submitted version and the official published version of record.

People interested in the research are advised to contact the author for the final version of the publication, or visit the DOI to the publisher's website.

- The final author version and the galley proof are versions of the publication after peer review.

- The final published version features the final layout of the paper including the volume, issue and page numbers.

Link to publication

\footnotetext{
General rights rights.

- You may freely distribute the URL identifying the publication in the public portal. please follow below link for the End User Agreement:

www.umlib.nl/taverne-license

Take down policy

If you believe that this document breaches copyright please contact us at:

repository@maastrichtuniversity.nl

providing details and we will investigate your claim.
}

Copyright and moral rights for the publications made accessible in the public portal are retained by the authors and/or other copyright owners and it is a condition of accessing publications that users recognise and abide by the legal requirements associated with these

- Users may download and print one copy of any publication from the public portal for the purpose of private study or research.

- You may not further distribute the material or use it for any profit-making activity or commercial gain

If the publication is distributed under the terms of Article $25 \mathrm{fa}$ of the Dutch Copyright Act, indicated by the "Taverne" license above, 


\title{
Monetary Union without Fiscal Coordination \\ May Discipline Policymakers
}

\author{
Roel M.W.J. Beetsma* \\ LIFE, University of Limburg, and CEPR \\ A. Lans Bovenberg \\ Central Planning Bureau and CEPR
}

\begin{abstract}
:
We show that, with benevolent policymakers and fiscal leadership, monetary unification reduces inflation, taxes and public spending. These disciplining effects of a monetary union, which rise with the number of fiscal players in the union, are likely to raise welfare. Joining an optimally designed monetary union is particularly attractive if fiscal authorities do not care about inflation. Fiscal coordination offsets the disciplining effects of monetary unification. Hence, subsidiarity in fiscal policymaking may enhance welfare.
\end{abstract}

Keywords: monetary union, fiscal leadership, common central bank, discipline, optimal institutions, inflation, taxation, spending, fiscal coordination.

JEL Codes: $\quad$ E52, E58, E61, E62, F42.

April 1995

Mailing address:

Roel Beetsma

LIFE/Department of Economics

University of Limburg

P.O.Box 616

6200 MD Maastricht

The Netherlands

* This paper was written while Beetsma was a postdoctoral fellow at DELTA (Joint Research Unit CNRS-EHESS-ENS), Paris. He thanks DELTA for the stimulating research environment. 


\section{Introduction}

Monetary developments in former Soviet republics and, most notably, the plans for European monetary unification initially set out in the Delors Report (1989) have brought monetary unification to the forefront of research agendas. Much of the literature suggests that monetary unification produces an inflationary bias and excessive public spending (Aizenman, 1992, 1993). ${ }^{1}$ The lack of monetary and fiscal discipline in a monetary union provides a case for fiscal coordination (see, e.g., Levine and Pearlman, 1992, Levine, 1993, Levine and Brociner, 1994, and Krichel, Levine and Pearlman, 1994). Furthermore, several papers find that the attractiveness of entering a monetary union or admitting a new participant decreases with the number of participants (see, e.g., Casella, 1990, Alesina and Grilli, 1993, and Bayoumi, 1994).

This paper provides a case against these findings. We set up a simple model of a monetary union with identical economies in which, in concluding nominal wage contracts, the private sector acts as Stackleberg leader versus the policy authorities (Barro and Gordon, 1983a,b). In setting tax rates, the fiscal authorities are in turn leader vis-à-vis the common central bank (CCB), which is unable to commit. ${ }^{2}$ After the CCB sets the inflation rate, public spending is set so as to balance the government budget. This description of fiscal-monetary interactions seems realistic because tax rates cannot be adjusted as quickly as monetary policy, so that a particular choice of tax rates provides the government with a first mover advantage (see also Debelle and Fischer, 1994).

Social welfare losses depend on deviations of inflation, output and public spending from their target levels. If policymakers share the objectives of society while lump-sum taxes and commitment are absent, insular policymaking (i.e. policymaking at the national level outside a monetary union) produces undisciplined policies. In particular, inflation, public spending and taxes are all excessive from a social perspective. Intuitively, discretionary policy uses unanticipated inflation, which is self-defeating in equilibrium, as an indirect instrument to alleviate tax distortions. A monetary union succeeds in alleviating this lack of discipline and the more so the larger the number of participants becomes. The reason is that a large union containing many noncooperating fiscal players strengthens the strategic position of the common central bank, which favors lower inflation than the fiscal players do because it does not internalize the beneficial impact of unanticipated inflation in relaxing government budget constraints. The resulting decline in inflation enhances welfare in modern economies in which small holdings of base money limit the adverse implications of lower inflation for seigniorage revenues.

The objectives of the fiscal authorities do not necessarily coincide with those of society. In

\footnotetext{
1 Aizenman $(1992,1993)$ shows that a monetary union with a large number of decision makers, who all have access to the printing of a common currency, suffers from excess public spending and an inflation bias. The main difference with our analysis is that we assume that the distribution of seigniorage revenues among policymakers is ex ante fixed.

${ }^{2}$ Commitment may also be partial, in the sense that under normal circumstances the policymaker sticks to its promises, while it deviates only in extreme cases (see Lohmann, 1992). Indeed, in practice it seems almost impossible to design institutions which rule out the possibility of reneging under extremely adverse circumstances (see Lohmann, 1995).
} 
particular, in contrast to society, fiscal authorities may not care about inflation. In that case, to offset the opportunistic behavior of the fiscal authorities, society finds it optimal to appoint an independent central bank that attaches a high priority to price stability. With such an optimally designed central bank, welfare losses decrease with the size of the union, irrespective of real money holdings. For a wide set of parameter combinations, numerical results suggest that increasing the size of an optimally designed union raises welfare also if fiscal authorities attach a positive weight to price stability.

Fiscal policy coordination produces the same outcomes as national policymaking outside a monetary union and, hence, eliminates the disciplining and potentially welfare enhancing effects of monetary unification. This provides a case for applying the subsidiarity principle to fiscal policymaking within a monetary union.

The remainder of this paper is structured as follows. Section 2 sets out the basic model. Section 3 explores the policy and welfare effects of monetary unification. This section investigates also the effects of fiscal coordination. Finally, Section 4 concludes the paper.

\section{The model}

The monetary union consists of $\mathrm{n}$ participating countries. Whereas the common central bank (CCB) sets monetary policy for the entire union, fiscal policy is determined at the national level by the $n$ governments. We follow Beetsma and Bovenberg (1995b) in modeling the $n$ national economies. For the purposes of this paper, we assume that all economies are identical. Each economy produces a single perfectly substitutable good. Capital is perfectly mobile across international borders while barriers to commodity trade are absent. Hence, the inflation rate is uniform across the union. Labor is immobile internationally. ${ }^{3}$

Consider some economy i $(i=1, . ., n)$. Following, among others, Alesina and Tabellini (1987), Debelle (1993), Eijffinger and Schaling (1993), Jensen (1994) and Beetsma and Bovenberg (1995a,b), workers are represented by trade unions whose sole objective is to achieve a target real wage rate, the logarithm of which we normalize to unity. Therefore, the (log) of the nominal wage rate is set equal to the (rationally) expected (log) price level, $\mathrm{p}^{\mathrm{e}}$, where the superscript " $\mathrm{e}^{\prime \prime}$ denotes an expectation. Nominal wage contracts are signed before policy is selected, so that unions act as Stackelberg leaders vis-a-vis the authorities.

Output of a representative firm in country $i$ amounts to $Y_{i}=L_{1}^{\eta}$, where $L_{i}$ is labor, and is taxed at a rate $\tau_{i}$. The firm maximizes profits, $P F^{\eta}\left(1-\tau_{i}\right)-W_{L}$, where $P$ and $W$ are price level and the wage rate (which is uniform across the entire union because the expected price level inflation is uniform across the union). Hence, $(\log )$ output is given by $y_{i}=(\eta /(1-\eta))\left(\pi-\pi^{e}-\tau_{i}+\log \eta\right)$, where $\pi$ is

\footnotetext{
${ }^{3}$ For the case of Europe, it is well known that labor is relatively immobile (for example, due to linguistic, cultural, social and institutional barriers).
} 
the inflation rate. For convenience, we normalize output by subtracting the constant $(\eta /(1-\eta)) \log \eta$ from $y_{\mathrm{i}}$. Without any consequences for our main results, we set $\eta=1 / 2$, so that normalized output, $x_{i}$, amounts to

$$
x_{i}=\pi-\pi^{e}-\tau_{i}
$$

In absence of tax distortions, $x_{i}=0$ in equilibrium (where $\pi=\pi^{e}$ ). We allow also for other, non-tax, distortions due to, for example, union power in the labor market. The first-best output level, i.e. output in the absence of any, tax or non-tax, distortion is $\tilde{x}$. Thus, $\tilde{x}>0$ measures the non-tax distortions and can be interpreted as an implicit tax on output. In fact, an output subsidy can offset the implicit output tax $\left(\tau_{\mathrm{i}}=-\tilde{\mathrm{x}}\right)$, thereby driving up output to the non-distortionary level $\tilde{\mathrm{x}}$.

Society i's welfare function is different from that of the unions, because it takes account of the preferences of not only workers but also non-workers. The following loss function defines society i's preferences over consumer price inflation, output and public spending:

$$
\mathrm{V}_{\mathrm{S}, \mathrm{i}}=1 / 2\left[\alpha_{\pi \mathrm{S}} \pi^{2}+\left(\mathrm{x}_{\mathrm{i}}-\tilde{\mathrm{x}}\right)^{2}+\alpha_{\mathrm{gS}}\left(\mathrm{g}_{\mathrm{i}}-\tilde{\mathrm{g}}\right)^{2}\right], \alpha_{\pi \mathrm{S}}, \alpha_{\mathrm{gS}}>0
$$

Welfare losses increase in the deviations of inflation, $(\mathrm{log})$ output, and government spending $\left(\mathrm{g}_{\mathrm{i}}\right.$ is government spending as a share of non-distortionary output) from their targets. ${ }^{4}$ The target level of inflation is set at zero, which corresponds to price stability, and the target for output amounts to the non-distortionary level, $\tilde{\mathbf{x}}$. The target for government spending, $\tilde{\mathbf{g}}$, can be interpreted as the optimal share of non-distortionary output to be spent on public goods if (non-distortionary) lump-sum taxes are available (Debelle and Fischer, 1994, and Beetsma and Bovenberg, 1995a). The parameters $\alpha_{\pi \mathrm{S}}$ and $\alpha_{\mathrm{gS}}$ denote the weights of the inflation and government spending objectives, respectively, relative to the weight of the output objective, which is normalized to unity. Only relative weights matter for the outcomes. The limiting case of $\alpha_{\mathrm{gs}} \rightarrow \infty$ corresponds to an exogenous government spending share equal to $\tilde{\mathrm{g}}$.

Country i's government features the following loss function:

$$
\mathrm{V}_{\mathrm{F}, \mathrm{i}}=1 / 2\left[\alpha_{\pi \mathrm{F}} \pi^{2}+\left(\mathrm{x}_{\mathrm{i}}-\tilde{\mathrm{x}}\right)^{2}+\alpha_{\mathrm{gS}}\left(\mathrm{g}_{\mathrm{i}}-\tilde{\mathrm{g}}\right)^{2}\right], \alpha_{\pi \mathrm{F}} \geq 0
$$

Hence, we allow the government's inflation weight, $\alpha_{\pi \mathrm{F}}$, to differ from the corresponding weight for society, $\alpha_{\pi \mathrm{s}}$. In particular, if $\alpha_{\mathrm{rF}}<\alpha_{\pi \mathrm{s}}$, the government is 'opportunistic' in the sense that it puts too high a relative weight on output and public spending. The government selects the tax rate and

${ }^{4}$ Note that output and employment are one to one related in the model. Hence, instead of output we could have included employment in the objective functions, with the target employment level corresponding to the output level in absence of any distortions. 
public spending under the restriction of its budget constraint, ${ }^{5}$

$$
\mathbf{g}_{\mathrm{i}}+\left(1+\rho+\pi^{\mathrm{e}}-\pi\right) \mathrm{d}=\tau_{\mathrm{i}}+\kappa \pi+\theta_{\mathrm{i}}
$$

where $\rho$ is the constant real interest rate and where $d \geq 0, \theta_{i}$ and $\kappa \geq 0$ (a constant) are, respectively, the exogenous stock of single-period non-indexed government debt, ${ }^{6}$ lump-sum tax revenue, and real money holdings as a share of output in absence of distortions. ${ }^{7}$ All countries share equally in the seigniorage of the CCB. Accordingly, seigniorage revenues accruing to country $i$ are given by $\kappa \pi$.

In equilibrium, expectations are rational and (2.4) can be rewritten as,

$$
\mathrm{K} \equiv \tilde{\mathrm{g}}+(1+\rho) \mathrm{d}+\tilde{\mathrm{x}}-\theta=\left[\tau_{\mathrm{i}}+\tilde{\mathrm{x}}\right]+\kappa \pi+\left[\tilde{\mathrm{g}}-\mathrm{g}_{\mathrm{i}}\right]
$$

where $\mathrm{K}$ represents the government financing requirement (see Beetsma and Bovenberg, 1995a). It amounts to the government spending target $\tilde{\mathbf{g}}$, debt servicing costs, $(1+\rho) \mathrm{d}$, and a labor subsidy aimed at offsetting the implicit tax on output, $\tilde{x}$, net of the maximum available amount of lumpsum taxes, $\theta<\tilde{\mathrm{g}}+(1+\rho) \mathrm{d}+\tilde{\mathrm{x}}$, which is equal for all countries. The last right-hand side of $\left(2.4^{\prime}\right)$ represents the three sources of finance: explicit and implicit tax revenues, $\tau_{\mathrm{i}}+\tilde{\mathrm{x}}$, seigniorage revenues, $\kappa \pi$ and the shortfall of government spending from its target, $\tilde{\mathrm{g}}-\mathrm{g}_{\mathrm{i}}$.

\section{Monetary union with fiscal leadership}

In setting taxes, the fiscal authorities act as Stackleberg leaders vis-à-vis the common monetary authority. In practice, fiscal leadership is likely to occur because monetary policy can be adjusted more quickly as fiscal policy so that a particular choice for taxes provides the fiscal authorities with a first-mover advantage versus the monetary authority. After the CCB sets inflation, the fiscal authorities set spending so as to balance the public budget.

An independent common central bank (CCB), which is unable to commit, sets monetary policy for the entire union. Its preferences are given by,

$$
\mathrm{V}_{\mathrm{CCB}}=1 / 2\left\{\alpha_{\pi \mathrm{M}} \pi^{2}+\sum_{\mathrm{i}=1} \mathrm{n}^{\mathrm{n}}\left[\left(\mathrm{x}_{\mathrm{i}}-\tilde{\mathrm{x}}\right)^{2}+\alpha_{\mathrm{gS}}\left(\mathrm{g}_{\mathrm{i}}-\tilde{\mathrm{g}}\right)^{2}\right] / \mathrm{n}\right\}, \alpha_{\pi \mathrm{M}}>0
$$

\footnotetext{
${ }^{5}$ The government budget constraint is derived in Beetsma and Bovenberg (1995a).

${ }^{6}$ Thus, $\rho+\pi^{\mathrm{e}}$ is the nominal interest rate, which compensates for the expected inflation incurred over the lifetime of the debt.

7 Alesina and Tabellini (1987), Debelle (1993) and Jensen (1994), among others, assume that $\kappa=1$. However, as will become clear, a non-unitary value of $\kappa$ plays an important role in our results.
} 
The CCB's public government spending weight coincides with societies' public spending weight, $\alpha_{\mathrm{gg} s}{ }^{8}$ Therefore, if $\alpha_{\mathrm{tM}}=\alpha_{\mathrm{tS}}$, the objective function of the CCB amounts to an equally weighted average of the individual societies' objective functions. The CCB sets the inflation rate so as to minimize (3.1) subject to $(2.1), \mathrm{i}=1, . ., \mathrm{n}$, and taking as given the taxes and public spending selected by the governments and the expected inflation rate, $\pi^{\mathrm{e}}$. This yields the following reaction function of the CCB:

$$
\pi=\left(\frac{1}{\alpha_{\pi M}+1}\right)\left(\pi^{\mathrm{e}}+\frac{1}{n} \sum_{i=1}^{\mathrm{n}}\left(\tau_{\mathrm{i}}+\tilde{\mathrm{x}}\right)\right),
$$

so that $\partial \pi / \partial \tau_{\mathrm{i}}=(1 / \mathrm{n})\left(1+\alpha_{\pi M}\right)^{-1}$ and $\partial \pi / \partial \mathrm{g}=0$. Higher expected inflation or higher taxes and non-tax labor market distortions in any of the participating countries induce the monetary authority to raise inflation in order to protect employment. However, the relative weight the CCB attaches to employment in country $i$ is only $1 / \mathrm{n}$-th of the weight that a national central bank would attach to employment if monetary policy would be determined at the national rather than the union level. As a direct consequence, the boost to inflation as a result of an increase in $\tau_{i}$ is only $1 / n$-th of the corresponding increase under national monetary policymaking. Therefore, the impact on the unionwide inflation rate of unilateral changes in the tax instrument declines when more countries participate in the union. Intuitively, in a larger union, the strategic position of an individual government vis-à-vis the CCB weakens.

Government $\mathrm{i}$ minimizes (2.3) over its two instruments $\tau_{\mathrm{i}}$ and $\mathrm{g}_{\mathrm{i}}$ subject to (2.1), (2.4) and the CCB's reaction function (3.2), while setting lump-sum taxes at their maximum $\theta<\tilde{g}+(1+\rho) d+\tilde{x}$. The resulting equilibrium policy outcomes are (see Appendix A)

$$
\kappa \pi=\left(\frac{\frac{\kappa}{\alpha_{\pi \mathrm{M}}}}{1+\frac{\kappa}{\alpha_{\pi \mathrm{M}}}+\frac{\gamma_{\mathrm{n}}}{\alpha_{\mathrm{gS}}}}\right) \tilde{\mathrm{K}}, \tau+\tilde{\mathrm{X}}=\left(\frac{1}{1+\frac{\kappa}{\alpha_{\pi \mathrm{M}}}+\frac{\gamma_{\mathrm{n}}}{\alpha_{\mathrm{gS}}}}\right) \tilde{\mathrm{K}}, \tilde{\mathrm{g}}-\mathrm{g}=\left(\frac{\frac{\gamma_{\mathrm{n}}}{\alpha_{\mathrm{gS}}}}{1+\frac{\kappa}{\alpha_{\pi \mathrm{M}}}+\frac{\gamma_{\mathrm{n}}}{\alpha_{\mathrm{gS}}}}\right) \tilde{\mathrm{K}},
$$

where we have suppressed the country index $i$, because the policy outcomes are uniform across the entire union and where

$$
\gamma_{\mathrm{n}} \equiv\left(\frac{\left(\frac{\mathrm{n}-1}{\mathrm{n}}\right)+\frac{1}{\mathrm{n}}\left(\frac{\alpha_{\pi \mathrm{F}}}{\alpha_{\pi \mathrm{M}}}\right)+\alpha_{\pi \mathrm{M}}}{1+\alpha_{\pi \mathrm{M}}+(\kappa+\mathrm{d}) / \mathrm{n}}\right)=1-\frac{(\kappa+\mathrm{d}) / \mathrm{n}}{1+\alpha_{\pi \mathrm{M}}+(\kappa+\mathrm{d}) / \mathrm{n}}-\frac{\frac{1}{\mathrm{n}}\left(\frac{\alpha_{\pi \mathrm{M}}-\alpha_{\pi \mathrm{F}}}{\alpha_{\pi \mathrm{M}}}\right)}{1+\alpha_{\pi \mathrm{M}}+(\kappa+\mathrm{d}) / \mathrm{n}} .
$$

Parameter $\alpha_{\mathrm{gs}}$ features in (3.3) because the fiscal authorities' public spending weight equals societies' public spending weight (see (2.3)). Of course, for $n=1,(3.3)$ coincides with the policy

\footnotetext{
${ }^{8}$ In fact, the CCB's public spending weight is irrelevant for the outcomes.
} 
outcomes under national monetary policymaking (see Beetsma and Bovenberg, 1995a). Expressions (3.3) and (3.4) reveal that fiscal leadership produces a "spending distortion". In particular, in the second best, ${ }^{9}$ and also in the Nash equilibrium, $(\tilde{\mathrm{g}}-\mathrm{g}) /(\tau+\tilde{\mathrm{x}})^{-1}=\alpha_{\mathrm{gS}}$. With fiscal leadership, in contrast, this ratio representing the tax-spending mix is given by $\gamma_{\mathrm{n}} / \alpha_{\mathrm{gs}}$. Hence, under fiscal leadership, the trade-off between high levels of public spending and low taxes producing high output is optimal only if $\gamma_{\mathrm{n}}$ equals unity. The smaller this parameter, the higher inflation, taxes, and public spending become.

The parameter $\gamma_{\mathrm{n}}$ thus plays an major role in our results. In particular, a non-unitary value for this parameter indicates that a conflict between the monetary and fiscal authorities gives rise to a spending bias. Expression (3.4) reveals the two potential origins of such a conflict. In particular, the next-to-last term at the right hand side of (3.4), which reduces $\gamma_{\mathrm{n}}$ below unity, arises because the CCB fails to internalize the government budget constraint. Accordingly, in contrast to the fiscal authorities, the CCB does not consider the fiscal benefits of inflation in terms of more seigniorage and unanticipated inflation in terms of less real debt service. Hence, the fiscal authorities raise taxes strategically to encourage the CCB to boost inflation in order to gain more seigniorage and reduce the real value of the non-indexed public debt. In particular, by increasing taxes, they induce the $\mathrm{CCB}$ to raise the inflation rate in order to protect employment. The additional tax revenues due to the strategic use of the tax instrument produce the spending bias. The fiscal benefits of inflation vanish if $\kappa+d=0$. In that case, the fiscal authorities do not have to raise taxes strategically to induce the CCB to indirectly internalize the government budget constraint so that the next-to-last term at the right-hand side of (3.4) thus becomes zero.

The last term on the right hand side of (3.4) originates in a conflict between the fiscal authorities and the CCB about inflation objectives. If the CCB is more inflation averse than the fiscal authorities $\left(\alpha_{\pi \mathrm{M}}>\alpha_{\pi \mathrm{F}}\right)$, the fiscal authorities raise taxes in order to encourage the CCB to produce more inflation, thereby bringing the equilibrium outcome more in line with the preferences of the fiscal authorities. This strategic use of the tax instrument produces a spending bias.

Expression (3.4) indicates that the spending bias due to the strategic use of the tax instrument vanishes in two special cases. First, if the union becomes very large (i.e. $\mathrm{n}$ approaches infinity), the last two terms at the right-hand side of (3.4) approach zero. The reason is that, with a large number of fiscal players, the impact of unilateral changes in the tax instrument on the behavior of the CCB becomes negligible. In this case, the price stability weight of the fiscal authority does not affect the policy outcomes at all. The reason is that the fiscal players perceive

\footnotetext{
${ }^{9}$ This is the equilibrium where all policy variables are selected by a benevolent policymaker, who is able to commit (see Beetsma and Bovenberg, 1995a). It corresponds to the Pareto optimal equilibrium given the government budget constraint.

${ }^{10}$ This is the equilibrium where both fiscal and monetary policymakers select their policies taking the other's policies as given (see Beetsma and Bovenberg, 1995a). With Nash behavior of both authorities, monetary unification would not have any impact as the resulting equilibrium in a monetary union would coincide with that under national monetary policymaking.
} 
that they do not have any impact any more on monetary decisions by the CCB. Hence, the CCB prevails in the conflict between the fiscal and monetary players about the optimal inflation rate. More generally, the larger the union, the weaker becomes the strategic position of each individual fiscal player and hence the smaller is the impact of the fiscal price stability weight on the policy outcomes.

The second case in which the strategic use of the tax instrument vanishes is if, at given $\alpha_{\pi \mathrm{F}}$, $\alpha_{\pi \mathrm{M}}$ goes to infinity. With an ultraconservative CCB (i.e. $\alpha_{\mathrm{M}} \rightarrow \infty$ ), the fiscal authorities realize that raising the tax rate will not induce the $\mathrm{CCB}$ to boost the inflation rate.

Substituting the policy outcomes (3.3) into the social loss function (2.1) and using that with rational expectations $x=-\tau$, we arrive at society i's loss in equilibrium,

$$
\mathrm{V}_{\mathrm{S}, \mathrm{i}}=\left(\frac{\frac{\alpha_{\pi \mathrm{S}}}{\alpha_{\pi \mathrm{M}}^{2}}+1+\frac{\gamma_{\mathrm{n}}^{2}}{\alpha_{\mathrm{gS}}}}{2\left(1+\frac{\kappa}{\alpha_{\pi \mathrm{M}}}+\frac{\gamma_{\mathrm{n}}}{\alpha_{\mathrm{gS}}}\right)^{2}}\right) \tilde{\mathrm{K}}^{2} .
$$

\section{Special case: policymakers share the social inflation objectives}

We first explore the case in which the preferences of both monetary and fiscal authorities coincide with societies' preferences (i.e. $\alpha_{\pi \mathrm{F}}=\alpha_{\pi \mathrm{M}}=\alpha_{\pi \mathrm{S}}$ ). In that case, the conflict between the monetary and fiscal authorities results in a spending distortion (i.e. $\gamma_{n}<1$, see (3.4)) as governments raise taxes strategically in order to induce the CCB to take into account the fiscal benefits of higher inflation. Moreover, a larger union, by weakening the strategic position of the fiscal players, reduces this spending bias (i.e. $\partial \gamma_{n} / \partial n>0$, see (3.4)).

To explore how the size of the union affects welfare in this case, we differentiate the equilibrium loss $\mathrm{V}_{\mathrm{S}, \mathrm{i}}$ (i.e. (3.5), with $\alpha_{\pi \mathrm{M}}=\alpha_{\pi \mathrm{S}}$ ) with respect to $\mathrm{n}$ :

$$
\frac{\partial \mathrm{V}_{\mathrm{S}, \mathrm{i}}}{\partial \mathrm{n}}=\left(\frac{\frac{\gamma_{\mathrm{n}}-1}{\alpha_{\mathrm{gS}}}+\frac{\gamma_{\mathrm{n}} \kappa-1}{\alpha_{\mathrm{gS}} \alpha_{\pi \mathrm{S}}}}{\left(1+\frac{\kappa}{\alpha_{\pi \mathrm{S}}}+\frac{\gamma_{\mathrm{n}}}{\alpha_{\mathrm{gS}}}\right)^{3}}\right)\left(\frac{\partial \gamma_{\mathrm{n}}}{\partial \mathrm{n}}\right) \tilde{\mathrm{K}}^{2} .
$$

As noted above, $\partial \gamma_{\mathrm{r}} / \partial \mathrm{n}>0$ as the spending distortion falls with the size of the union. Hence, a larger union benefits welfare if the term between the first square brackets is negative. The two terms in the numerator of this term stand for the first-order welfare effects of changes in, respectively, public spending and inflation. The first term in the numerator is always negative, indicating that lower public spending (allowing for lower taxes, thereby raising output) unambiguously raises welfare because this spending is excessively high under fiscal leadership due 
to the strategic use of the tax instrument. The larger is the magnitude of the spending distortion (as indicated by the absolute value of $\gamma_{\mathrm{n}}-1$ ), the larger becomes the first-order welfare gain associated with a lower level of public spending and a higher level of output.

The second term in the numerator represents the welfare impact of the lower inflation rate that is produced by a larger union. The sign of this effect depends on the size of real money holdings, as represented by $\kappa$. In particular, a lower inflation rate benefits welfare if $\kappa \leq 1$. Intuitively, with relatively small money holdings, the fiscal benefits of inflation in generating seigniorage revenues are relatively unimportant. Accordingly, inflation is excessively high from a social point of view because the CCB attempts to use unanticipated inflation as an instrument to boost output, thereby alleviating distortions in the real economy. With rational expectations, this attempt is ineffective as the private sector anticipates this incentive of discretionary policy to employ monetary policy in this way. With excessive inflation in the initial equilibrium, the reduction in inflation produced by the expansion of the monetary union pushes inflation closer towards the socially optimal rate (see Beetsma and Bovenberg, 1995a), thereby producing a firstorder gain in welfare.

\section{Policymakers do not share the social inflation objectives}

Before investigating how the size of the union impacts policies and welfare at arbitrary levels of $\alpha_{\pi \mathrm{M}}$ and $\alpha_{\pi \mathrm{F}}$, we need to explore the properties of $\gamma_{\mathrm{n}}$. First, in most cases $\gamma_{\mathrm{h}}$ will be lower than one, indicating that the fiscal authorities prefer a higher inflation rate than the CCB does so that they raise taxes strategically to encourage the CCB to boost inflation (in particular $\gamma_{\mathrm{n}}<1$ if $\alpha_{\pi \mathrm{F}}<(\kappa+d+1) \alpha_{\pi \mathrm{M}}$, see (3.4)). However, if the fiscal authorities attach a much higher priority to price stability than the CCB does (i.e. $\alpha_{\pi \mathrm{F}}>(\kappa+\mathrm{d}+1) \alpha_{\pi \mathrm{M}}$ so that $\gamma_{\mathrm{h}}>1$, see (3.4)), they actually cut taxes strategically in order to induce the CCB to reduce inflation. In that case, $\gamma_{n}$ is decreasing rather than increasing in the size of the union:

$$
\frac{\partial \gamma_{\mathrm{n}}}{\partial \mathrm{n}}=\frac{\left(1+1 / \alpha_{\pi \mathrm{M}}\right)\left(\alpha_{\pi \mathrm{M}}(\kappa+\mathrm{d}+1)-\alpha_{\pi \mathrm{F}}\right)}{\left(\mathrm{n}\left(1+\alpha_{\pi \mathrm{M}}\right)+\kappa+\mathrm{d}\right)^{2}}
$$

Hence, a larger union always moves $\gamma_{\mathrm{n}}$ towards unity. Intuitively, in a larger union, governments find it less attractive to use the tax instrument strategically to affect common monetary policy set by the CCB. Hence, the trade off between low taxes and high spending moves closer to its social optimum.

To see how, for arbitrary price stability weights of the CCB and the fiscal authorities, the size of the union affects welfare, we differentiate $V_{\mathrm{S}, \mathrm{i}}(3.5)$ with respect to $\mathrm{n}$ : 


$$
\frac{\partial \mathrm{V}_{\mathrm{S}, \mathrm{i}}}{\partial \mathrm{n}}=\left(\frac{\frac{\gamma_{\mathrm{n}}-1}{\alpha_{\mathrm{gS}}}+\frac{1}{\alpha_{\mathrm{gS}} \alpha_{\pi \mathrm{M}}}\left(\kappa \gamma_{\mathrm{n}}-\frac{\alpha_{\pi \mathrm{S}}}{\alpha_{\pi \mathrm{M}}}\right)}{\left(1+\frac{\kappa}{\alpha_{\pi \mathrm{M}}}+\frac{\gamma_{\mathrm{n}}}{\alpha_{\mathrm{gS}}}\right)^{3}}\right)\left(\frac{\partial \gamma_{\mathrm{n}}}{\partial \mathrm{n}}\right) \tilde{\mathrm{K}}^{2} .
$$

The first term in the numerator of the term between the first square brackets at the right-hand side of (3.8) represents the welfare effects of changes in the trade off between higher public spending and lower taxes producing higher output. The second term between the first square brackets indicates how changes in the inflation rate impact welfare. In combination with $\partial \gamma_{\mathrm{r}} / \partial \mathrm{n}$, the first term always raises welfare as a larger union reduces the strategic use of the tax instrument and thus reduces the distortion in the level of public spending. The sign of the welfare impact of changes in inflation as a result of the larger union depends on the specific parameter values. Unless the fiscal authorities care much more about price stability than the CCB does, a larger union reduces inflation as the fiscal authorities put less effort into inducing the CCB to raise inflation (i.e. $\alpha_{\pi \mathrm{F}}<(\kappa+d+1) \alpha_{\pi \mathrm{M}}$ so that $\left.\partial \gamma_{n} / \partial n>0\right)$. This produces a first-order welfare gain if inflation is too high from a social point of view, indicating that the monetary authorities are not conservative enough (this is the case if $\alpha_{\pi \mathrm{M}}<\alpha_{\pi \mathrm{s}} / \kappa$, see expression (3.9) below). Accordingly, an increase in the size of the union unambiguously enhances welfare if $\alpha_{\pi \mathrm{F}}<(\kappa+\mathrm{d}+1) \alpha_{\pi \mathrm{M}}<(\kappa+\mathrm{d}+1) \alpha_{\pi \mathrm{S}} / \kappa$.

\section{Optimal institutions in a monetary union}

We now turn to the question how policies and welfare are affected by joining a properly designed monetary union. If society can optimally adjust both fiscal and monetary institutions, the second-best optimum can be achieved by selecting the following preference weights for price stability

$$
\alpha_{\pi \mathrm{F}}^{\mathrm{opt}}=\alpha_{\pi \mathrm{S}}(\kappa+\mathrm{d}+1) / \kappa \text { and } \alpha_{\pi \mathrm{M}}^{\mathrm{opt}}=\alpha_{\pi \mathrm{s}} / \kappa .^{11}
$$

Accordingly, the fiscal authorities should be made more conservative than both the central bank and society (see Beetsma and Bovenberg, 1995a). The reason is that the fiscal authorities internalize the benefits of inflation in relaxing the government budget constraint. Hence, they face an especially strong incentive to boost inflation.

As long as central bank preferences can be adjusted properly (i.e. $\alpha_{\pi \mathrm{M}}=\alpha_{\pi \mathrm{M}}{ }^{\text {opt }}$ ), the adjustment of the fiscal price stability weight $\alpha_{\pi \mathrm{F}}$ becomes less important if the size of the union increases. To demonstrate this, we substitute $\alpha_{\pi \mathrm{M}}^{\text {opt }}$ from (3.9) into (3.5) and note that $\mathrm{V}_{\mathrm{S}, \mathrm{i}}$ equals

${ }^{11}$ These weights are found by noting that the second best requires that $(\tilde{\mathrm{g}}-\mathrm{g}) /(\tau+\tilde{\mathrm{x}})=\alpha_{\mathrm{gS}}^{-1}$ and, hence, that $\gamma_{\mathrm{n}}=1$. Combine this with the requirement that the inflation rate be equal to the second best rate. This yields the optimal CCB inflation weight, $\alpha_{\pi \mathrm{M}}{ }^{\mathrm{opt}}=\alpha_{\pi \mathrm{S}} / \mathrm{K}$. Substitute this expression for $\alpha_{\mathrm{M}}$ into the equation $\mathrm{n}_{\mathrm{n}} \gamma=1$ to yield the optimal inflation weight of the fiscal authority, $\alpha_{\pi \mathrm{F}}{ }^{\text {opt }}$. 
the second-best welfare loss if $\gamma_{\mathrm{n}}=1$ (see Beetsma and Bovenberg, 1995a). Furthermore, we substitute $\alpha_{\pi M}^{\text {opt }}$ into (3.4) to find,

$$
\gamma_{\mathrm{n}}=\left(\frac{\left(\frac{\mathrm{n}-1}{\mathrm{n}}\right)+\frac{\kappa}{\mathrm{n}}\left(\frac{\alpha_{\pi \mathrm{F}}}{\alpha_{\pi \mathrm{S}}}\right)+\frac{\alpha_{\pi \mathrm{S}}}{\kappa}}{1+\alpha_{\pi \mathrm{S}} / \kappa+(\kappa+\mathrm{d}) / \mathrm{n}}\right) .
$$

The fiscal authorities' inflation weight affects $\gamma_{n}$ only through the second term in the numerator of (3.10). The relative importance of this term falls with the size of the union, $n$. The diminishing importance of optimally adjusting the fiscal price stability weight reflects again the weaker strategic position of the fiscal players in a larger union. As noted earlier, if $n \rightarrow \infty$, the fiscal authorities' inflation weight becomes completely irrelevant, because they are unable to affect the common monetary policy. In that case, the second-best is reached by adjusting the CCB's inflation aversion only (i.e. by setting $\alpha_{\pi \mathrm{M}}=\alpha_{\pi \mathrm{M}}{ }^{\text {opt }}$ ). Therefore, in a very large union, fiscal preferences do not have to be adjusted.

In practice, society may not be able to change the preferences of the fiscal authorities. Hence, the rest of this section explores what happens if society can optimally select only the preferences of the CCB. A particularly interesting case is when the fiscal authorities do not care about inflation at all $\left(\alpha_{\pi \mathrm{F}}=0\right)$. For that case, one can show (see Appendix B) that the optimally designed $\mathrm{CCB}$ is more conservative than when also fiscal preferences can be adjusted (i.e. $\left.\alpha_{\pi M}{ }^{\text {opt }}>\alpha_{\pi S} / \kappa\right)$. Intuitively, a relatively conservative CCB is required to offset the pressure exerted by opportunistic fiscal authorities to boost inflation. Moreover, irrespective of real money holdings, enlarging a monetary union raises welfare as long as the price stability weight of the CCB is set optimally (see Appendix C).

Another interesting case is when money holdings become negligible (i.e. $\kappa=0$ ). In that case, making the central bank ultraconservative (i.e. giving it an infinite preference weight for price stability) is sufficient for attaining the second-best, irrespective of the size of the union. ${ }^{12}$ The reason is that the optimal inflation rate is zero because inflation does not provide any social benefits by generating seigniorage. An ultraconservative CCB not only produces zero inflation but it also makes the fiscal players realize that the strategic use of taxes is futile, thereby avoiding the spending distortion.

Finally, we consider the case in which the fiscal authorities share societies' degree of inflation aversion $\left(\alpha_{\pi \mathrm{F}}=\alpha_{\pi \downarrow}\right.$. For this case, we have not been able to establish unambiguous analytical results concerning the welfare effects of an increase in the size of a monetary union with an optimally designed CCB. Accordingly, we resorted to numerical simulations for a wide variety

\footnotetext{
${ }^{12}$ If $\alpha_{\pi \mathrm{M}} \rightarrow \infty, \gamma_{\mathrm{n}} \rightarrow 1$ and, hence, $\mathrm{V}_{\mathrm{S}, \mathrm{i}} \rightarrow 1 / 2\left(1+\alpha_{\mathrm{gS}}\right)^{-1}$, which equals the second-best welfare loss if $\kappa=0$.
} 
of parameter combinations. ${ }^{13}$ For all of the parameter combinations investigated, we found that the welfare loss was decreasing in $n$ when $\alpha_{\pi M}{ }^{\text {opt }}$ was optimally adjusted.

${ }^{13}$ We used a grid made up of all the possible combinations of the following parameter values: for $\alpha_{\pi S}, \alpha_{g S}$ and $\kappa$ we used the values $0.1,0.5,1,2$ and 10 ; for $d$ we used 0,1 and 2 ; for $n$ we chose $1,2,3,5$ and 10 . This yields a total of 1875 parameter combinations. 


\section{Fiscal coordination can be counterproductive}

Fiscal coordination changes the strategic interactions. In the absence of coordination, the effect of unilateral changes in the tax instrument on the common monetary policy is relatively small, especially if the monetary union becomes large (see equation (3.1)). This discourages governments from using the tax instrument strategically vis-a-vis the CCB. With coordination, however, each fiscal player internalizes the effects of a unilateral tax change on the other fiscal players. This encourages the fiscal authorities to employ their tax instruments so as to encourage the CCB to change the inflation rate in the direction preferred by the fiscal players. In this way, fiscal cooperation strengthens the strategic position of the fiscal authorities.

With fiscal coordination, tax rates and public spending levels are selected by a supranational authority who minimizes an equally weighted sum of the individual fiscal authorities' loss functions. Not surprisingly, with symmetric countries, fiscal coordination yields the same policy outcomes as under national policymaking (Appendix D). Hence, if policymakers share the social preferences, fiscal coordination weakens discipline as inflation, taxes and public spending all increase. Therefore, with low money holdings and hence small social benefits from seigniorage, fiscal coordination harms welfare. As shown above, with completely opportunistic fiscal authorities (i.e. $\alpha_{\pi \mathrm{F}}=0$ ) and an optimally designed CCB, fiscal coordination is always counterproductive, irrespective of real money holdings. Moreover, the numerical results discussed earlier suggest that fiscal coordination unambiguously deteriorates welfare with an optimally designed CCB, also if fiscal authorities do care about inflation. Hence, if the fiscal players coordinate, an appropriate adjustment of fiscal preferences for price stability becomes more important in order to prevent excessive inflation and public spending. However, changing fiscal preferences may be difficult to implement in practice. Hence, our results strengthen the case for subsidiarity in fiscal policymaking to reduce spending and inflation biases originating in the inability to commit. ${ }^{14}$

\section{Conclusions}

This paper has demonstrated that, under fiscal leadership, monetary unification may discipline fiscal and monetary policy, thereby reducing inflation, taxes and public spending. In modern economies with relatively small money holdings, the disciplining effects of monetary union boost welfare. For such economies, the attractiveness of joining a monetary union increases in its size. Intuitively, in a union with an increasing number of fiscal players, the strategic position of each of the fiscal authorities weakens. This reduces inflation and public spending, thereby offsetting the inflation bias due to the absence of commitment and the spending bias due to the strategic use

14 Using a different model, Rogoff (1985) shows that monetary policy coordination may be counterproductive, because coordination may worsen the credibility problem of central banks vis-à-vis the private sector. Thus, Rogoff (1985) provides another example of the general result that coordination among a subset of players may be counterproductive, because removing one distortion (i.e. the failure to internalize externalities) may exacerbate another distortion (absence of commitment). 
of the tax instrument. By restoring the strategic position of the fiscal players vis-à-vis the monetary authorities, fiscal policy coordination destroys the disciplining effect of a union.

When the fiscal authorities do not care about inflation at all, a larger union with an optimally designed CCB unambiguously raises welfare, irrespective of the size of money holdings. To counteract the opportunistic fiscal players, the CCB should be made more conservative than in the absence of fiscal leadership (i.e. in the second best). However, the optimal price stability weight of the CCB converges to that in the second best (i.e. in the absence of fiscal leadership) if the union becomes infinitely large. For the case of benevolent fiscal authorities, numerical results reveal that increasing the size of an optimally designed union raises welfare.

\section{References:}

Aizenman, J. (1992), 'Competitive Externalities and the Optimal Seigniorage', Journal of Money, Credit, and Banking, 24, 61-71.

Aizenman, J. (1992), 'Soft Budget Constraints, Taxes, and the Incentive to Cooperate', International Economic Review, 34, 819-32.

Alesina, A. and V.U. Grilli (1993), 'On the Feasibility of a One or Multi-Speed European Monetary Union', NBER Working Paper, No.4350.

Alesina, A. and G. Tabellini (1987), 'Rules and Discretion with Non-Coordinated Monetary and Fiscal Policies', Economic Inquiry, 25, pp.619-30.

Barro, R.J. and D.B. Gordon (1983a), 'A Positive Theory of Monetary Policy in a Natural Rate Model, Journal of Political Economy, 91, 589-610.

Barro, R.J. and D.B. Gordon (1983b), 'Rules, Discretion and Reputation in a Model of Monetary Policy, Journal of Monetary Economics, 12, 101-21.

Bayoumi, T. (1994), 'A Formal Model of Optimum Currency Areas', CEPR Discussion Paper, No.968.

Beetsma, R.M.W.J. and A.L. Bovenberg (1995a), 'Designing Fiscal and Monetary Institutions in a Second-Best World', mimeo, DELTA and CentER.

Beetsma, R.M.W.J. and A.L. Bovenberg (1995b), 'Designing Fiscal and Monetary Institutions for a European Monetary Union', mimeo, DELTA and CentER.

Casella, A. (1990), 'Participation in a Currency Union', NBER Working Paper, No.3220.

Debelle, G. (1993), 'Central Bank Independence: A Free Lunch?', mimeo, MIT.

Debelle, G. and S. Fischer (1994), 'How Independent Should a Central Bank Be?', CEPR Publication, No.392.

Delors Report (1989), 'Report on Economic and Monetary Union in the European Community', Commission of the European Communities, Brussels.

Eijffinger, S.C.W. and E. Schaling (1993), 'Central Bank Independence: Theory and Evidence', mimeo, Tilburg University.

Jensen, H. (1994), 'Loss of Monetary Discretion in a Simple Monetary Policy Game', Journal of Economic Dynamics and Control, 18, 763-79.

Krichel, T., Levine, P. and J. Pearlman (1994), 'Fiscal and Monetary Policy in a Monetary Union: Credible Inflation Targets or Monetised Debt?', mimeo, University of Surrey.

Levine, P. (1993), 'Fiscal Policy Co-ordination under EMU and the Choice of Monetary Instrument', The Manchester School, 41, 1-12, Supplement.

Levine, P. and A. Brociner (1994), 'Fiscal Policy Coordination and EMU', Journal of Economic Dynamics and Control, 18, 699-729.

Levine, P. and J. Pearlman (1992), 'Fiscal and Monetary Policy under EMU: Credible Inflation Target or Unpleasant Monetarist Arithmetic?', CEPR Discussion Paper, No. 701.

Lohmann, S. (1992), 'Optimal Commitment in Monetary Policy: Credibility versus Flexibility', American Economic Review, 82, 273-86.

Lohmann, S. (1995), 'Why Do Central Banking Institutions Matter?', in Eijffinger, S.C.W. and H. Huizinga, Positive Political Economy: Theory and Evidence, John Wiley \& Sons, New 
York.

Rogoff, K. (1985), 'Can International Monetary Policy Cooperation be Counter-Productive?', Journal of International Economics, 18, 199-217. 


\section{Appendices}

\section{A: Derivation of policy outcomes (3.3).}

The reaction function of the CCB (3.2) has already been derived in the main text.

The Lagrangian of the fiscal authority of country $i$ is,

$$
1 / 2\left[\alpha_{\pi \mathrm{F}} \pi^{2}+\left(\pi-\pi^{\mathrm{e}}-\tau_{\mathrm{i}}-\tilde{\mathrm{x}}\right)^{2}+\alpha_{\mathrm{gS}}\left(\mathrm{g}_{\mathrm{i}}-\tilde{\mathrm{g}}\right)^{2}\right]+\lambda\left[\mathrm{g}_{\mathrm{i}}+\left(1+\rho+\pi^{\mathrm{e}}-\pi\right) \mathrm{d}-\tau_{\mathrm{i}}-\kappa \pi-\theta\right]
$$

where $\pi$ is given by the CCB's reaction function (3.2). The first order conditions for taxes and public spending are,

$$
\begin{gathered}
\alpha_{\pi \mathrm{F}} \pi\left(\frac{\partial \pi}{\partial \tau_{\mathrm{i}}}\right)+\left(\pi-\pi^{\mathrm{e}}-\tau_{\mathrm{i}}-\tilde{\mathrm{x}}\right)\left(\frac{\partial \pi}{\partial \tau_{\mathrm{i}}}-1\right)=\lambda\left((\kappa+\mathrm{d})\left(\frac{\partial \pi}{\partial \tau_{\mathrm{i}}}\right)+1\right), \\
\alpha_{\mathrm{gS}}\left(\tilde{\mathrm{g}}-\mathrm{g}_{\mathrm{i}}\right)=\lambda,
\end{gathered}
$$

where $\partial \pi / \partial \tau_{i}$ is evaluated along the reaction curve of the CCB (3.2). Because the economies are identical, in equilibrium fiscal policies are the same for all countries and, hence, in equilibrium, $\pi=\left(\tau_{i}+\tilde{x}\right) / \alpha_{\pi M}$ Substitute this expression into (A.2), also substitute $\partial \pi / \partial \tau_{i}=(1 / n)\left(1+\alpha_{\pi M}\right)^{-1}$ (from the CCB's reaction function) into (A.2), impose rational expectations $\left(\pi^{\mathrm{e}}=\pi\right)$ on $(\mathrm{A} .2)$, multiply both sides by $\left(1+\alpha_{\pi \mathrm{M}}\right)$ and rearrange, to yield:

$$
\left(\left(\frac{\mathrm{n}-1}{\mathrm{n}}\right)+\frac{1}{\mathrm{n}}\left(\frac{\alpha_{\pi \mathrm{F}}}{\alpha_{\pi \mathrm{M}}}\right)+\alpha_{\pi \mathrm{M}}\right)\left(\tau_{\mathrm{i}}+\tilde{\mathrm{X}}\right)=\lambda\left(1+\alpha_{\pi \mathrm{M}}+\left(\frac{\kappa+\mathrm{d}}{\mathrm{n}}\right)\right) .
$$

Substitute (A.3) into (A.4) to yield,

$$
\tilde{\mathrm{g}}-\mathrm{g}_{\mathrm{i}}=\left(\frac{\gamma_{\mathrm{n}}}{\alpha_{\mathrm{gS}}}\right)\left(\tau_{\mathrm{i}}+\tilde{\mathrm{x}}\right)
$$

Substitute (A.5) and $\kappa \pi=\kappa\left(\tau_{i}+\tilde{x}\right) / \alpha_{\pi M}$ into the government financing requirement $\left(2.4^{\prime}\right)$ and rewrite to yield the solution for $\tau_{i}+\tilde{x}$. The solutions for the other policy instruments follow easily.

B: Proof that if $\alpha_{\pi \mathrm{F}}=0$ and $\kappa>0$, the optimal CCB is more conservative then $\alpha_{\pi \mathrm{S}} / \kappa$.

$$
\begin{aligned}
& \text { If } \alpha_{\pi \mathrm{F}}=0, \\
& \qquad \gamma_{\mathrm{n}}=\frac{(\mathrm{n}-1) / \mathrm{n}+\alpha_{\pi \mathrm{M}}}{1+\alpha_{\pi \mathrm{M}}+(\kappa+\mathrm{d}) / \mathrm{n}}<1,
\end{aligned}
$$

and, hence,

$$
\frac{\partial \gamma_{\mathrm{n}}}{\partial \alpha_{\pi \mathrm{M}}}=\frac{(\kappa+\mathrm{d}+1) / \mathrm{n}}{\left(1+\alpha_{\pi \mathrm{M}}+(\kappa+\mathrm{d}) / \mathrm{n}\right)^{2}}>0
$$


Differentiate $\mathrm{V}_{\mathrm{S}, \mathrm{i}}$ with respect to $\alpha_{\pi \mathrm{M}}$ and rearrange to find that the sign of $\partial \mathrm{V}_{\mathrm{S}, \mathrm{i}} / \partial \alpha_{\pi \mathrm{M}}$ is given by the sign of,

$$
A+B\left(\frac{\partial \gamma_{n}}{\partial \alpha_{\pi M}}\right)
$$

where

$$
\begin{gathered}
\mathrm{A} \equiv \frac{1}{\alpha_{\pi \mathrm{M}}^{2}}\left(\kappa-\frac{\alpha_{\pi \mathrm{S}}}{\alpha_{\pi \mathrm{M}}}\right)+\frac{\gamma_{\mathrm{n}}}{\alpha_{\pi \mathrm{M}}^{2} \alpha_{\mathrm{gS}}}\left(\kappa \gamma_{\mathrm{n}}-\frac{\alpha_{\pi \mathrm{S}}}{\alpha_{\pi \mathrm{M}}}\right), \\
\mathrm{B} \equiv \frac{1}{\alpha_{\mathrm{gS}}}\left(\gamma_{\mathrm{n}}-1\right)+\frac{1}{\alpha_{\pi \mathrm{M}} \alpha_{\mathrm{gS}}}\left(\kappa \gamma_{\mathrm{n}}-\frac{\alpha_{\pi \mathrm{S}}}{\alpha_{\pi \mathrm{M}}}\right)
\end{gathered}
$$

Note, also for later use, that for $\alpha_{\pi \mathrm{M}}$ close enough to zero, $\mathrm{A}$ and $\mathrm{B}$ are both negative and, hence $\partial \mathrm{V}_{\mathrm{S}, \mathrm{i}} / \partial \alpha_{\pi \mathrm{M}}$ is negative. Moreover, if $\kappa>0$, for $\alpha_{\pi \mathrm{M}}$ large enough, $\mathrm{A}$ and $\mathrm{B}$ are both positive and, hence, $\partial \mathrm{V}_{\mathrm{S}, \mathrm{l}} / \partial \alpha_{\pi \mathrm{M}}$ is positive. Hence, if $\kappa>0$, there exists a value of $\alpha_{\pi M}$ between zero and infinity at which $V_{S, i}$ reaches a global minimum and at which $\partial \mathrm{V}_{\mathrm{S}, \mathrm{l}} / \partial \alpha_{\pi \mathrm{M}}=0$. Denote this optimal value for $\alpha_{\pi \mathrm{M}}$ by $\alpha_{\pi \mathrm{M}}{ }^{\mathrm{opt}}$.

Because $\gamma_{\mathrm{n}}<1$, we have that $\mathrm{A}<0$ and $\mathrm{B}<0$ for $\alpha_{\pi \mathrm{M}} \leq \alpha_{\pi \mathrm{S}} / \kappa$ and, hence, that $\partial \mathrm{V}_{\mathrm{S}, \mathrm{i}} / \partial \alpha_{\pi \mathrm{M}}<0$ for $\alpha_{\pi \mathrm{M}} \leq \alpha_{\pi \mathrm{S}} / \kappa$. Hence, there can be no optimum $0<\alpha_{\pi M}{ }^{\text {opt }} \leq \alpha_{\pi} \mathrm{d} / \kappa$.

\section{C: Proof that an increase in the size of a union with an optimal CCB raises welfare}

\section{if $\alpha_{\pi \mathrm{F}}=0$ and the degree of CCB conservatism is optimally adjusted}

Note that if, $\alpha_{\pi \mathrm{F}}=0$, an increase in $\mathrm{n}$ raises $\gamma_{\mathrm{n}}$. Differentiate $\mathrm{V}_{\mathrm{S}, \mathrm{i}}$ with respect to $\gamma_{\mathrm{n}}$ which yields,

$$
\frac{\partial \mathrm{V}_{\mathrm{S}, \mathrm{i}}}{\partial \gamma_{\mathrm{n}}}=\left(\frac{\left(\frac{\gamma_{\mathrm{n}}-1}{\alpha_{\mathrm{gS}}}\right)+\left(\frac{\gamma_{\mathrm{n}} \kappa-\alpha_{\pi \mathrm{S}} / \alpha_{\pi \mathrm{M}}}{\alpha_{\mathrm{gS}} \alpha_{\pi \mathrm{M}}}\right)}{\left(1+\frac{\kappa}{\alpha_{\pi \mathrm{M}}}+\frac{\gamma_{\mathrm{n}}}{\alpha_{\mathrm{gS}}}\right)^{3}}\right) \tilde{\mathrm{K}}^{2} \text {. }
$$

Clearly, for $\kappa=0, \partial V_{S, i} / \partial \gamma_{n}<0$. Remember that for $\kappa>0$, there exists a value of $\alpha_{\mathrm{tM}}$ between zero and infinity at

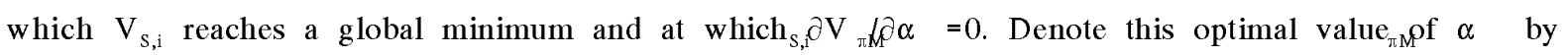
$\alpha_{\pi M}{ }^{\mathrm{opt}}(\mathrm{n})$.

Note that the numerator in the coefficient of $K^{2}$ equals $B$ (B.5). If we can show that this numerator is negative, then a marginal increase in $n$ reduces welfare loss, given $\alpha_{\pi M}=\alpha_{\pi M}{ }^{\text {opt }}(n)$.

Because $\gamma_{\mathrm{n}}<1, \partial \mathrm{Y}_{\mathrm{i}} / \partial \gamma$ can only be non-negative $\mathrm{f}_{\mathrm{M}}$ if $\mathrm{\pi S}_{\mathrm{n}} \alpha \alpha / \kappa \gamma$. Therefore, suppose that $\alpha_{\pi M}{ }^{\text {opt }}(\mathrm{n})>\alpha_{\pi \mathrm{S}} / \kappa \gamma_{\mathrm{n}}$ and that $\mathrm{B} \geq 0$. Again, because ${ }_{\mathrm{n}} \gamma<1$, this implies that $\mathrm{A}>0 \mathrm{if}_{\mathrm{M}} \alpha_{\pi} \overline{\overline{\mathrm{M}}} \mathrm{\alpha}^{\mathrm{pt}} \quad$ (n). Combine this with (B.2) and (B.3), to imply that $\partial V_{S, i} / \partial \alpha_{\pi M}>0$ if $\alpha_{\pi M}=\alpha_{\pi M}{ }^{\text {opt }}(n)$. This yields a contradiction, so that $\alpha_{\pi M}{ }^{\text {opt }}(n)$ cannot be an optimum or B cannot be non-negative. Hence, at an optimum $\alpha_{\pi M}=\alpha_{\pi M}{ }^{\text {opt }}(n), \partial V_{S, j} / \partial \gamma_{n}<0$.

The result that a marginal increase in $n$ reduces welfare losses when evaluated at $\alpha_{\pi M}=\alpha_{\pi M}{ }^{\text {opt }}(n)$ is independent of $\mathrm{n}$. Hence, if we increase the number of participants from $\mathrm{m} \geq 1$ (where $\mathrm{m}$ is integer), with 
$\alpha_{\pi M}=\alpha_{\pi M}{ }^{\text {opt }}(\mathrm{m})$, to $\mathrm{m}+1$, adjusting $\alpha_{\pi \mathrm{M}}$ to $\alpha_{\pi \mathrm{M}}{ }^{\text {opt }}(\mathrm{m}+1)$, welfare losses will be reduced (because they are reduced for all subsequent marginal increases in $n$, while adjusting $\alpha_{\pi M}$ optimally).

D: Proof that fiscal coordination yields the same outcomes as insular fiscal policymaking.

The Lagrangian of the supranational fiscal policymaker is given by,

$$
1 / 2\left\{\alpha_{\pi \mathrm{F}} \pi^{2}+\sum_{\mathrm{i}=1}^{\mathrm{n}}\left[\left(\pi-\pi^{\mathrm{e}}-\tau_{\mathrm{i}}-\tilde{\mathrm{x}}\right)^{2}+\alpha_{\mathrm{gS}}\left(\mathrm{g}_{\mathrm{i}}-\widetilde{\mathrm{g}}\right)^{2}\right] / \mathrm{n}\right]+\sum_{\mathrm{i}=1}{ }^{\mathrm{n}} \lambda_{\mathrm{i}}\left[g_{\mathrm{i}}+\left(1+\rho+\pi^{\mathrm{e}}-\pi\right) \mathrm{d}-\tau_{\mathrm{i}}-\kappa \pi-\theta\right]
$$

where $\pi$ is given by the CCB's reaction function (3.2). The first-order conditions for taxation and public spending in country $\mathrm{i}$ are,

$$
\begin{gathered}
\alpha_{\pi \mathrm{F}} \pi\left(\frac{\partial \pi}{\partial \tau_{\mathrm{i}}}\right)+\frac{1}{\mathrm{n}} \sum_{\mathrm{j}=1, \mathrm{j} \neq \mathrm{i}}^{\mathrm{n}}\left(\pi-\pi^{\mathrm{e}}-\tau_{\mathrm{j}}-\tilde{\mathrm{x}}\right)\left(\frac{\partial \pi}{\partial \tau_{\mathrm{i}}}\right)+\frac{1}{\mathrm{n}}\left(\pi-\pi^{\mathrm{e}}-\tau_{\mathrm{i}}-\tilde{\mathrm{x}}\right)\left(\frac{\partial \pi}{\partial \tau_{\mathrm{i}}}-1\right)= \\
\sum_{\mathrm{j}=1, \mathrm{j} \neq \mathrm{i}}^{\mathrm{n}} \lambda_{\mathrm{j}}(\kappa+\mathrm{d})\left(\frac{\partial \pi}{\partial \tau_{\mathrm{i}}}\right)+\lambda_{\mathrm{i}}\left((\kappa+\mathrm{d})\left(\frac{\partial \pi}{\partial \tau_{\mathrm{i}}}\right)+1\right), \\
\alpha_{\mathrm{gS}}\left(\tilde{\mathrm{g}}-\mathrm{g}_{\mathrm{i}}\right) / \mathrm{n}=\lambda_{\mathrm{i}},
\end{gathered}
$$

where $\partial \pi / \partial \tau_{i}=(1 / n)\left(1+\alpha_{\pi M}\right)^{-1}$. Again, because the economies are identical, in equilibrium fiscal policies are the same for all countries and, hence, in equilibrium, $\pi=\left(\tau_{i}+\tilde{x}\right) / \alpha_{\pi M}$. Substitute this expression into (D.2), also substitute $\partial \pi / \partial \tau_{i}=(1 / n)\left(1+\alpha_{\pi M}\right)^{-1}$ into (D.2), impose rational expectations $(\pi=\pi)$ on (D.2), use that (in equilibrium) $\tau_{j}=\tau_{i}$, multiply both sides by $n\left(1+\alpha_{\pi M}\right)$ and rewrite, to yield:

$$
\left(\frac{\alpha_{\pi \mathrm{F}}}{\alpha_{\pi \mathrm{M}}}+\alpha_{\pi \mathrm{M}}\right)\left(\tau_{\mathrm{i}}+\tilde{\mathrm{x}}\right)=\sum_{\mathrm{j}=1}^{\mathrm{n}} \lambda_{\mathrm{j}}(\kappa+\mathrm{d})+\lambda_{\mathrm{i}} \mathrm{n}\left(1+\alpha_{\pi \mathrm{M}}\right)
$$

Because in equilibrium public spending is the same for all countries, (D.3) implies that the Lagrange multipliers are the same for all $\mathrm{j}=1, . ., \mathrm{n}$. Use this and substitute (D.3) into (D.4), to yield,

$$
\left(\frac{\alpha_{\pi \mathrm{F}}}{\alpha_{\pi \mathrm{M}}}+\alpha_{\pi \mathrm{M}}\right)\left(\tau_{\mathrm{i}}+\tilde{\mathrm{x}}\right)=\alpha_{\mathrm{gS}}\left(1+\alpha_{\pi \mathrm{M}}+\kappa+\mathrm{d}\right)\left(\tilde{\mathrm{g}}-\mathrm{g}_{\mathrm{i}}\right) .
$$

Combine (D.5) and $\kappa \pi=\left(\tau_{i}+\tilde{x}\right) / \alpha_{\pi M}$ with the government financing requirement $\left(2.4^{\prime}\right)$ to obtain the equilibrium policies. These coincide with the outcomes in (3.3) for $n=1$. 